\title{
Aurélien Boivin, Hans-Jürgen Lüsebrink et Jacques Walter, Régionalismes littéraires et artistiques comparés Québec/Canada-Europe
}

Jean-François Plamondon

\section{(2) OpenEdition}

Journals

Édition électronique

URL : http://journals.openedition.org/studifrancesi/4507

DOI : $10.4000 /$ studifrancesi.4507

ISSN : 2421-5856

Éditeur

Rosenberg \& Sellier

\section{Édition imprimée}

Date de publication : 1 septembre 2016

Pagination : 382-383

ISSN : 0039-2944

\section{Référence électronique}

Jean-François Plamondon, « Aurélien Boivin, Hans-Jürgen Lüsebrink et Jacques Walter, Régionalismes littéraires et artistiques comparés Québec/Canada-Europe ", Studi Francesi [En ligne], 179 (LX | II) | 2016, mis en ligne le 01 septembre 2016, consulté le 18 septembre 2020. URL : http://

journals.openedition.org/studifrancesi/4507 ; DOI : https://doi.org/10.4000/studifrancesi.4507

Ce document a été généré automatiquement le 18 septembre 2020.

\section{c) $(9 \odot$}

Studi Francesi è distribuita con Licenza Creative Commons Attribuzione - Non commerciale - Non opere derivate 4.0 Internazionale. 


\title{
Aurélien Boivin, Hans-Jürgen Lüsebrink et Jacques Walter, Régionalismes littéraires et artistiques comparés Québec/Canada-Europe
}

\author{
Jean-François Plamondon
}

\section{RÉFÉRENCE}

AURÉLIEN BOIVIN, HANS-JÜRGEN LÜSEBRINK et JACQUES WALTER, Régionalismes littéraires et artistiques comparés Québec/Canada-Europe, Nancy, Presses universitaires de Nancy, 2014, $308 \mathrm{pp}$.

1 Le sujet pouvait sembler déjà vu, déjà lu, voire déjà digéré comme si rien de neuf n'eut pu sortir d'un tel exercice. Pourtant, quelque chose de nouveau et d'original émane des ces remarquables actes, dont le colloque nous eût intéressé au plus haut point. Régionalismes littéraires et artistiques comparés Québec/Canada-Europe, actes d'un colloque universitaire qui eut lieu en Europe en 2007. Sept longues années avant que ne paraissent les actes de ce stimulant colloque, d'autant plus intéressant que malgré les années qui séparent le colloque de la publication des actes, les articles d'intérêt n'ont pris aucune ride. Quoique ce compte rendu doive tenir compte des contributions extraeuropéennes, il nous semble aller de soi de souligner l'article inaugural du professeur VON UNGEM-STERNBERG de l'Université de Mayence, qui s'interroge sur la pertinence du concept de littérature régionale. Existe-t-il un tel type de représentation culturelle et si oui, quels sont les critères qui le définissent? Le professeur de Mayence conclut son exposé en affirmant que oui, une littérature régionale existe mais non pas par des "paysages à travers lesquels nous voyageons», mais par le «style, les mécanismes de représentation, les traditions et les genres» (p.30). Un des grands avantages du comparatisme, c'est que l'étude d'un corpus national entre en résonance avec un autre 
corpus et que de cette rencontre émanent des ressemblances et dissemblances entre les deux corps qui se visitent. Il est d'ailleurs évident que celui qui parle de régionalisme parle aussi d'espaces relativement conscrits et que si le régionalisme existe, il n'est pas représentatif d'un territoire national. En se penchant sur la littérature transfrontalière franco-allemande, le professeur SCHOLDT de l'Université de La Sarre fait ressortir un ensemble de critères constitutifs de la littérature de cette région, qui fut l'objet de nombreux conflits entre la France et l'Allemagne. Il paraît dès lors raisonnable d'imaginer qu'un régionalisme lorrain n'ait rien à voir avec un régionalisme breton, provençal ou québécois. C'est pourquoi, il était aussi juste de rappeler comme l'avait fait précédemment le professeur de Mayence que le régionalisme est une histoire de forme et non pas une histoire de paysage. Le professeur David KAREL, à la mémoire duquel les actes sont dédiés, amène une contribution d'un grand intérêt. En étudiant le régionalisme dans la peinture québécoise, il valorise un rapprochement entre la littérature et l'art régionalistes au Québec qui ne s'est jamais faite, par simple manque de «hauteur adéquate» (p.76). Il faut en effet rappeler à quel point le régionalisme littéraire a souvent été accompagné d'illustrations de peintre qui ont aussi marqué profondément le goût québécois. Cet apport d'un professeur en art perturbe considérablement le paisible champ du régionalisme. «Le besoin est grand de mieux connaître le régionalisme en tant que conséquence et phénomène de la modernité, au même titre que le modernisme. Je me demande plus précisément si cette obstination à vouloir consigner le régionalisme aux limbes de la marginalité n'est pas en soi le réflexe d'une modernisme révolu, et à ce titre le symptôme d'un paradigme historique en mal de révision»(p.78). Il est vrai que les promoteurs du régionalisme sont souvent considérés par la critique institutionnelle comme des conservateurs, alors que les modernistes jouissent d'une réputation de progressistes. Le professeur de l'Université Laval prend toutefois plaisir à rappeler que «le modernisme, aussi, peut charrier un discours conservateur, ainsi que les exemples du futurisme italien ou de l'expressionnisme allemand le démontrent (je pense à Emil Nolde)» (p.78). Arrivent ensuite d'intéressants articles d'Aurélien Borvin qui livre une étude comparant l'œuvre de René Bazin et celle de Damas Potvin, et celui de Brigitte NADEAU qui propose un article sur le projet régionaliste d'Albert Pelletier, projet qui n'est pas sans rappeler les petites choses de l'histoire de Pierre-Georges Roy, en ce que «l'amour de la grande patrie [pour Pelletier] naît de l'attachement à la petite patrie, celle qui est à notre mesure et à notre portée» (p.138). La contribution de Maurice LEMIRE, autre digne représentant de l'Université Laval, apporte un renouvellement de la dynamique régionaliste québécoise. Eu égard à l'expression française dont le régionalisme s'oppose à une langue par trop parisienne et peu représentative de la diversité des français parlés en France, le régionalisme québécois est un courant révélant «la véritable langue canadienne», qui s'oppose non pas au français de Québec ou de Montréal, mais à l'anglicisation. Hans-Jürgen LÜSEBRINK de l'Université de La Sarre étudie quant à lui un type d'imprimé qui a fait fortune au Québec: l'almanach. Étrange support qui, en plus des prévisions annuelles de météo et des conditions sociales nouvelles, publiait des pages de littérature régionaliste et construisait un tissu social propre à la création d'une identité régionale. À son tour, Kenneth LANDRY livre un excellent article sur la traduction des écrits paysans et apporte aussi beaucoup à la réflexion sur cette époque régionaliste. L'Acadie, enfin, n'est pas en reste avec sa littérature régionale, Hélène DESTREMPES démontre en effet qu'un courant littéraire visant à anoblir le peuple acadien s'opposait à un métissage du sang indien. Construire son identité contre celle des 
peuples jugés moins évolués, telle était l'idéologie promue par la littérature dans une Acadie en soif de reconnaissance, à une époque ou les expressions "métis" et "bâtard" partageaient la même bulle sémantique. 